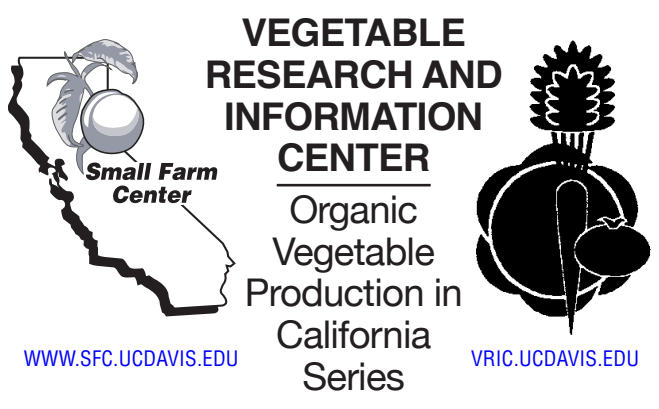

\section{SOIL FERTILITY MANAGEMENT FOR ORGANIC CROPS}

MARK GASKELL, UC Cooperative Extension Farm Advisor, Santa Barbara and San Luis Obispo Counties; RICHARD SMITH, UCCE Farm Advisor, Monterey and Santa Cruz Counties; JEFF MITCHELL, UCCE Vegetable Crops Specialist, Kearney Agricultural Center, Parlier; STEVEN T. KOIKE, UCCE Farm Advisor, Monterey and Santa Cruz Counties; CALVIN FOUCHE, UCCE Farm Advisor, San Joaquin County; TIM HARTZ, UCCE Vegetable Crops Specialist, UC Davis; WILLIAM HORWATH, Professor of Soils and Biogeochemistry, UC Davis; and LOUISE JACKSON, UCCE Vegetable Crops Specialist, UC Davis.

Specific information on organic vegetable production practices in California is scarce, and growers need sound information to guide their management decisions. The Organic Vegetable Production in California Series is made up of publications written by Farm Advisors and Specialists from the University of California's Division of Agriculture and Natural Resources. Each publication addresses a key aspect of organic production practices applicable to all vegetable crops.

Growers need sound information to guide their management decisions on organic vegetable production practices in California, yet pecific information is scarce. The Organic Vegetable Production in California Series consists of publications written by farm advisors and specialists from the University of California's Division of Agriculture and Natural Resources. Each publication addresses a key aspect of organic production practices applicable to all vegetable crops.

Organic soil fertility management is guided by the philosophy of "feed the soil to feed the plant." This basic precept is implemented through a series of practices designed to increase soil organic matter, biological activity, and nutrient availability. For the current list of approved practices for organic certification, see the USDA National Organic Program (NOP) Web site at http://www.ams.usda.gov/nop/indexIE.htm. Adding organic materials such as cover crops, crop residues, and composts to cultivated soils over time builds soil organic matter and improves the ability of the soil to supply nutrients. The ultimate goal is a healthy, fertile, biologically active soil with improved structure and enhanced nutrient availability. Organic management practices strive to optimize diverse biological processes in the soil to create a complex environment that ensures adequate nutrition to the crop. For a discussion of related soil management practices, see Soil Management and Soil Quality for Organic Crops (UC ANR Publication 7248, http://anrcatalog.ucdavis. edu/pdf/7248.pdf).

\section{ROLE OF ORGANIC MATTER AND HUMUS}

Increasing soil organic matter is a key aspect of an organic production system. The formation and decomposition of soil organic matter are fundamental life-promoting processes that store and release energy derived from photosynthesis. Soil organic matter is mainly the product of microbial and faunal decomposition of plant residues. The decomposition of plant residue leads to the formation of humic substances, which constitute 70 to 80 percent of the organic matter in most soils. The remaining soil organic matter is termed "light fraction" or "particulate organic matter" and is composed of a continuum of material ranging from recently deposited litter to highly decomposed unrecognizable plant residues. Soils with higher clay contents in temperate climates generally have the most soil organic matter. In California, organic matter typically makes up 1 to 3 percent of the dry weight of cultivated agricultural soils and 4 to 6 percent of untilled pasture soils. Studies have shown that it is normally not possible to increase soil organic matter by more than 1 percent, but even an increase of this much can dramatically improve soil fertility.

During the formation of soil organic matter, nutrients such as nitrogen $(\mathrm{N})$, phosphorus $(\mathrm{P})$, and sulfur (S) are incorporated into the soil structure, allowing the soil to act as a reservoir of these and other nutrients. The decomposition of soil organic matter releases nutrients, at which point they become available for plant uptake. Generally, 2 to 5 percent of soil organic matter decomposes annually. Soil organic matter 
contains a number of fractions that vary in composition and activity. Humus is the most resistant and mature fraction of soil organic matter. It is very slow to decompose and may last for hundreds of years. Plant residues that are high in carbon (C) and low in nitrogen, such as straw or cornstalks, decompose slowly but are efficient producers of humus. Residues that contain high levels of nitrogen, such as young cereals and legumes, decompose quickly, producing less humus. Although the process of organic matter formation is not well understood, it is clear that increasing the amount of soil humus improves soil properties and crop growth.

The decomposition of organic matter in soils can provide significant quantities of several important nutrients. A portion of the nitrogen from organic matter is converted into plant-available mineral forms such as ammonium $\left(\mathrm{NH}_{4}^{+}\right)$and nitrate $\left(\mathrm{NO}_{3}{ }^{-}\right)$ through the process of mineralization. However, the timing and amount of mineralization often do not coincide with crop need, making in-season fertilization necessary. This lack of synchrony between nitrogen mineralized from organic matter and crop nitrogen uptake is a major challenge for fertility management in organic systems. Organic matter is a good source of phosphorus; as phosphorus is mineralized from organic matter it becomes available for plant growth or becomes bound to soil minerals. Organic matter is also a significant source of micronutrients such as iron (FE), copper ( $\mathrm{Cu})$ and zinc $(\mathrm{Zn})$.

In addition to supplying nutrients, soil organic matter improves soil fertility by imparting favorable chemical and physical attributes to soil. Soil organic matter can bind nutrients through the process of cation exchange. Ammonium $\left(\mathrm{NH}_{4}{ }^{+}\right)$, calcium (Ca), magnesium $(\mathrm{Mg})$, and potassium $(\mathrm{K})$ are nutrient cations that are held on cation exchange sites on organic matter. The cation exchange capacity of soil organic matter can contribute from 20 to 70 percent of the total cation exchange capacity of soil. Soil structure is influenced by the association of soil organic matter with minerals to form aggregates. Aggregate formation improves soil structure and water infiltration and increases water-holding water capacity. These changes improve root growth and provide habitat for a diversity of soil organisms. Soil organic matter enhances nutrient cycling, provides habitat for a diversity of soil organisms, and creates a favorable environment for plant growth.

\section{HOW TO DETERMINE NUTRIENT NEEDS}

Crop nutrient requirements and the nutrient-supplying capacity of the soil dictate the management practices necessary for successful crop production. Soil testing is essential for the assessment of nutrient levels, and it is often required for organic certification. Management of nutrients such as phosphorus, potassium, calcium, magnesium, and sulfur should be directed toward raising these nutrients to optimal levels in the soil as determined by soil testing. Phosphorus availability in soils with $\mathrm{pH}$ greater than 6.0 is assessed by the Olsen bicarbonate test; for soils with $\mathrm{pH}$ less than 6.0 the Bray test is used. In most vegetable production areas in California soil $\mathrm{pH}$ is greater than 6.0, so this discussion will focus on the Olsen bicarbonate soil test. Natural levels of phosphorus in most California soils were formerly less than $30 \mathrm{ppm}$. Over years of fertilization for commercial vegetable production, fields now routinely have soil phosphorus greater than $60 \mathrm{ppm}$ along the coast, and somewhat less in the interior valleys. Phosphorus availability is reduced at low soil temperatures (i.e., $<60^{\circ} \mathrm{F}$, or $15.6^{\circ} \mathrm{C}$ ) and, as a result, crops grown in the cooler part of the year need higher levels of available soil phosphorus for good growth. Approximate soil adequacy values from the bicarbonate phosphorus test for warmand cool-season vegetables are given in table 1 .

Table 1. Adequate soil phosphorus levels (bicarbonate phosphorus test)

\begin{tabular}{|l|c|}
\hline Crop & $\begin{array}{c}\text { Adequate soil } \\
\text { P level (ppm) }\end{array}$ \\
\hline warm-season vegetables & $20-25$ \\
\hline cool-season vegetables & $50-60$ \\
\hline
\end{tabular}

Compost and certain organic fertilizers are good sources of phosphorus. It is important to monitor soil phosphorus levels on a yearly basis, as soil phosphorus can rapidly build up high to levels when composts and other organic amendments are used. Excessive soil phosphorus can result in high phosphorus concentration in field runoff, which can impair the quality of surface waters such as rivers, creeks, and lakes.

Soil potassium level is best determined by an ammonium acetate extraction test. In general, if soil potassium is greater than $200 \mathrm{ppm}$, no increase in yield is likely to be obtained with additional potassium fertilization. However, maintenance applications of potassium may be helpful in replacing soil potassium that is removed in the crop. For soils at less than $150 \mathrm{ppm}$ potassium, fertilization is warranted. Composts and some organic fertilizers are good sources of potassium.

Calcium, magnesium, and sulfur are usually present in the soil and in irrigation water in sufficient quantities to adequately supply a crop. In very sandy soils with low levels of organic matter, sulfur availability may be limited, but normal organic practices (application of compost, use of sulfur as a fungicide) typically maintain adequate levels of soil sulfur. While neither calcium nor magnesium availability is 
often limiting for crop nutrition, in some fields relatively low soil calcium and/or high magnesium content can result in poor soil structure and slow water infiltration. In these circumstances application of gypsum (naturally occurring calcium sulfate) is the most appropriate remedy.

In organic systems, appropriate nitrogen management cannot be directly inferred from a simple soil test. Unlike conventional production, in which nitrogen management is based on the use of soluble, readily available nitrogen fertilizers, in organic systems nitrogen management is based on manipulating organic sources of nitrogen; organic nitrogen must be mineralized through the action of soil microbes before it is available for plant uptake. Although this process can supply a significant quantity of nitrogen, estimating the amount and timing of nitrogen mineralization is complicated because a number of factors affect the process. The most important of these factors are as follows.

- Soil temperature: Mineralization is insignificant below $50^{\circ} \mathrm{F}\left(10^{\circ} \mathrm{C}\right)$, but above that temperature, mineralization increases as soil temperature increases.

- Soil moisture: Mineralization proceeds rapidly in moist soils, but is inhibited by either excessively wet or dry conditions.

- Tillage practices: Soil tillage stimulates a temporary burst of microbial activity, which declines over the course of days or weeks.

Despite the complex interactions of these factors, a rough estimate of mineralization from soil organic matter can be made based on the amount of organic nitrogen present in the soil and the percentage of that nitrogen likely to mineralize over a given period of time. The following procedure describes a method for estimating the amount of nitrogen likely to be mineralized from soil organic matter.

The first step is to estimate the amount of organic nitrogen in the soil. This can be done directly by a specialized laboratory test, or it can be inferred from the soil organic matter content. In most agricultural soils, organic nitrogen constitutes approximately 7 percent of soil organic matter. The vast majority of nitrogen mineralization takes place in the top 1 foot $(30 \mathrm{~cm})$ of soil. A standard estimate of soil weight is 4,000,000 pounds of dry soil per acre-foot (about 1,816,000 kg / 100 cubic meters). The organic nitrogen content of a soil with 1 percent organic matter would be

$4,000,000 \mathrm{lb}$ soil $\times 0.01$ (percent organic matter) $\times$ 0.07 (percent $\mathrm{N}$ in organic matter) $=2,800 \mathrm{lb}$ organic $\mathrm{N} /$ acre $(3,136 \mathrm{~kg} / \mathrm{ha})$
The second step is to estimate the percentage of soil organic nitrogen likely to mineralize during the crop cycle. Laboratory incubation studies of dozens of California soils have shown that, at best, about 2 percent of soil organic nitrogen is mineralized in a 2-month period at $77^{\circ} \mathrm{F}\left(25^{\circ} \mathrm{C}\right)$. For a soil with 1 percent organic matter, that would be

$2,800 \mathrm{lb}$ organic $\mathrm{N} /$ acre $\times 0.02$ (percent of organic nitrogen that mineralizes $)=56 \mathrm{lb}$ plant-available $\mathrm{N} /$ acre $(63 \mathrm{~kg} / \mathrm{ha})$

The 2 percent estimate for nitrogen availability for a short-term annual crop can be adjusted to fit field-specific conditions based on the factors previously described. Fields that are sprinkler-irrigated keep the entire soil surface moist, while much of the surface soil in drip-irrigated fields may be very dry. The soil temperature during spring and fall crops is lower than that for summer crops. Fields in which any form of reduced tillage is practiced tend to have slower nitrogen mineralization. Heavy clay soil is more readily waterlogged by rain or irrigation, and effective nitrogen mineralization may be reduced. Note that this technique for estimating nitrogen mineralization from soil organic matter does not take into account the nitrogen contribution from recently incorporated crop residue, compost, or other organic amendments. These contributions are described elsewhere in this publication.

Synchronizing nitrogen mineralization from soil organic matter, cover crop residues, and organic amendments to maintain adequate nitrogen availability for crop production is challenging. The generalized pattern of nitrogen mineralization and crop nitrogen uptake is presented in figure 1 . The rate of nitrogen mineralization from soil organic matter and recently incorporated residues and amendments typically peaks before the crop reaches its maximum rate of nitrogen uptake. Even in organic systems, nitrogen loss through leaching or denitrification (conversion of nitrate to gaseous nitrogen in wet soil and subsequent loss to the atmosphere) can be substantial if excessive water from rain or irrigation is applied to the field in the early weeks of the growing season.

Short-season crops with low nitrogen requirements such as leafy greens and radishes (table 2) may produce well with the nitrogen available from soil organic matter plus cover crop residues and/or a compost application. Crops with higher nitrogen requirements and longer growing seasons often need supplemental sidedress applications of organic nitrogen fertilizer. For many vegetable crops, quality is as important as yield. Product size, color, and uniformity can be critical, and nitrogen management is often the key to maximizing these quality attributes. 
Table 2. Nitrogen requirement of vegetable crops based on seasonal nitrogen uptake

\begin{tabular}{|c|c|c|}
\hline $\begin{array}{c}\text { Low total N content } \\
\mathbf{<} \mathbf{1 2 0} \mathbf{~ l b} / \text { acre }\end{array}$ & $\begin{array}{c}\text { Medium total N content } \\
\mathbf{1 2 0}-\mathbf{2 0 0} \mathbf{l b} / \text { acre }\end{array}$ & $\begin{array}{c}\text { High total N content } \\
>\mathbf{2 0 0} \mathbf{l b} / \text { acre }\end{array}$ \\
\hline baby greens & carrot & broccoli \\
beans & corn, sweet & cabbage \\
\hline cucumbers & garlic & cauliflower \\
radish & lettuce & celery \\
spinach & melons & potato \\
squashes & onion & \\
\hline & peppers & \\
\hline
\end{tabular}

Figure 1. Timing of nitrogen mineralization from soil organic matter, cover crop residue, and organic fertilizer in relation to crop nitrogen uptake.

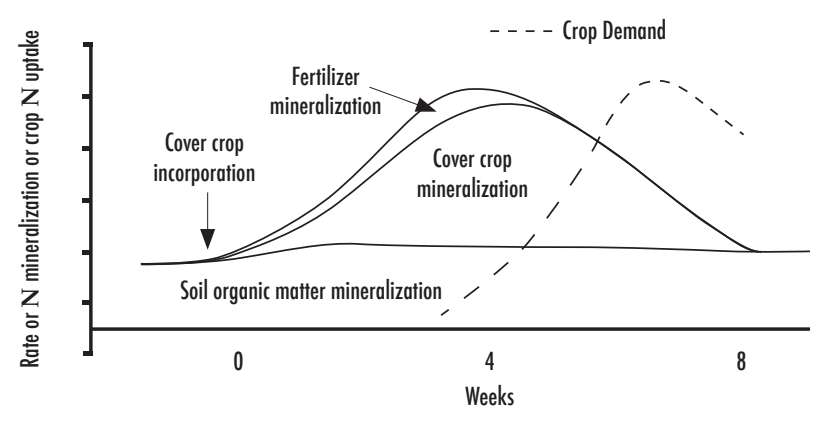

\section{NUTRIENT SOURCES}

\section{Cover Crops}

Cover crops fix and trap nutrients, add organic matter to soils, and reduce nitrate leaching, nutrient runoff, and soil erosion. In California, cover crops are widely used in organic farming systems because the climate is mild enough to support growth during the fall, winter, and early spring in most crop production areas. Nonleguminous cover crops, such as grasses and Brassica species, are preferred in situations where nutrient availability is high in the fall and where cover crops can trap nitrate and phosphate that would otherwise be lost by leaching or runoff. Nonlegumes also tend to be more tolerant of cooler temperatures than legumes. Legumes fix atmospheric nitrogen, at least when concentrations of mineral nitrogen in the soil are low, and add to the net availability of nitrogen in the cropping system. Mixtures of legumes and grasses are a common strategy because the grass consumes soil nitrogen, avoiding high soil nitrogen concentrations than might otherwise inhibit fixation. Mixtures also ensure that the cover crop is productive under a range of weather condition, due to the different environmental tolerances of the various plant species.

In California, cover crops typically take up or fix from 100 to 200 pounds of nitrogen per acre (112 to $224 \mathrm{~kg} / \mathrm{ha}$ ). Cover crops are often tilled into the soil when the carbon to nitrogen $(\mathrm{C}: \mathrm{N})$ ratio is less than 20:1 (e.g., legumes and younger stages of cereals and mustards) to achieve a net release of nitrogen to the soil in order to feed subsequent vegetable crops. The high nitrogen content in cover crops reduces competition for mineral nitrogen between the subsequent vegetable crop and the soil microbiota. When cover crops with a low nitrogen content, such as mature cereals (i.e., C:N ratio $>20: 1$ ) are incorporated into the soil, subsequent vegetable crops can be temporally nitrogen deficient because soil microbes use available soil nitrogen to break down the cover crop residue. However, these cover crops with a higher C:N ratio are instrumental in building soil organic matter, which is advantageous for long-term soil fertility and improvements in soil physical properties. A longer-term grass or brassica cover crop is therefore recommended periodically, as long as cropping patterns permit a sufficient period without crop production for residue decomposition to occur.

Less than half of the amount of nitrogen in a cover crop typically becomes available to the subsequent crop. Much of the cover crop nitrogen remains in resistant organic forms in soil organic matter, unavailable to plants. The organic nitrogen in the readily decomposable fraction of cover crop residues, however, can be very rapidly mineralized to plant-available forms of nitrogen in the first few weeks after incorporation. The rate of mineralization of available nitrogen from a cover crop with a low $\mathrm{C}$ : $\mathrm{N}$ ratio $(<20: 1)$ increases over a 3- to 6-week period following incorporation, and then returns to preincorporation levels by weeks 6 to 8 (see fig. 1). Therefore, a cover crop can be a valuable short-term source of nitrogen, but longer-season vegetable crops following a cover crop rotation may require additional applications of nitrogen later in the season. When nitrogen from cover crops is mineralized it can be taken up and used by the crop or lost via leaching during spring rainy periods. For this rea- 
son, vegetable crops should be planted relatively soon after cover crop incorporation, although the cover crop should be allowed to decompose for at least 3 to 4 weeks in order to avoid potential stand establishment and pest problems that may arise as the residue decomposes.

\section{Compost}

Compost, particularly if it contains animal manure, can be a relatively cost-effective organic source of both macro- and micronutrients. When applying compost, the challenges are to know its composition and to understand how to use it most efficiently. The grower should know the composting process used by the supplier as well as the sources of the raw material in the compost. If the materials that are being composted are low in nutrients, the compost will have a low nutrient analysis. Poor-quality or immature compost may actually tie up nitrogen in the soil and decrease the availability of nitrogen to the growing crop. The C:N ratio of a compost is one indication of nitrogen availability. As the $\mathrm{C}: \mathrm{N}$ ratio rises above 20:1, the tendency for nitrogen from the soil to be tied up increases. A compost with a C:N ratio of less than 20:1 generally releases nitrogen to the succeeding crop. Other quality considerations for compost are age, particle size, $\mathrm{pH}$, salt concentration, and purity (the volume of soil, sand, and other nonorganic materials mixed with the compost). The National Organic Program (Section 205.203) describes additional standards for compost sources (see the NOP Web site). Because compost analysis is based on dry weight, moisture content adds to the compost's weight and lowers its nutrient analysis. It is not unusual for a commercial compost to have a moisture content of 25 to 30 percent.

Mineralization rates from compost application are relatively low, and compost is usually a poor short-term source of nitrogen. Recent studies have shown that typically no more than 15 percent of the nitrogen in the compost is made available the first year following incorporation. This may in part explain problems with nitrogen fertilization often observed during the transition from conventional to organic production. A longer-term program of repeated compost application would be required to increase the overall amount of soil organic nitrogen and increase the nitrogen mineralization potential.

\section{Manure}

Aged animal manure can be a balanced source of nitrogen and other major and minor nutrients. Manure can be used in organic production only if it is applied to non-food-crop land, or incorporated into the soil at least 120 days prior to harvest if the edible portion is in contact with the soil, or incorporated into the soil at least 90 days prior to harvest if the edible portion is not in contact with the soil. One potential limitation of manure is the availability of a consistent supply of a material that is uniform enough to be confidently incorporated into a production program. A public perception of food-safety problems relating to manure fertilization might further limit the use of manure, and it is important to check with potential buyers to be certain that they do not have internal policies restricting manure use. Most manure used in organic vegetable production is composted prior to field application, which minimizes food-safety risks.

\section{Commercial Organic Fertilizers}

A number of approved organic fertilizers are available; common examples are listed in table 3. Most of these materials are by-products of fish, livestock, and food processing industries. The commercial formulations and nutrient analyses of these materials vary considerably. In general, they range from 0 to 12 percent nitrogen and may contain phosphorus and/or potassium. These fertilizers tend to be quite expensive, and in general their use is confined to situations where cover cropping or the application of compost is not feasible or has supplied insufficient nutrient availability for the upcoming cash crop. The value of these fertilizers lies in relatively rapid availability of the nutrients contained.

Table 3. Nutrient analysis (percent) of common organic fertilizer materials

\begin{tabular}{|l|c|c|c|}
\hline Material & $\begin{array}{c}\text { Nitrogen } \\
(\mathbf{\%})\end{array}$ & $\begin{array}{c}\text { Phosphorus } \\
\left(\mathbf{\%} \mathbf{P}_{\mathbf{2}} \mathbf{O}_{5}\right)\end{array}$ & $\begin{array}{c}\text { Potassium } \\
\left(\mathbf{\%} \mathbf{K}_{\mathbf{2}} \mathbf{O}\right)\end{array}$ \\
\hline chilean nitrate & 16 & 0 & 0 \\
\hline blood meal & 12 & 0 & 0 \\
\hline feather meal & $12-11$ & 0 & 0 \\
\hline $\begin{array}{l}\text { fish meal } \\
\text { or powder }\end{array}$ & $9-12$ & $3-8$ & 2 \\
\hline $\begin{array}{l}\text { seabird and } \\
\text { bat guano }\end{array}$ & 8 & 5 & $1-2$ \\
\hline meat and bone meal & 7 & 2 & 1 \\
\hline soybean meal & 4 & 2 & 2 \\
\hline $\begin{array}{l}\text { processed liquid fish } \\
\text { residues }\end{array}$ & 4 & 1 & 1 \\
\hline alfalfa meal & $2-4$ & 1.5 & 1.5 \\
\hline $\begin{array}{l}\text { pelleted chicken } \\
\text { manure }\end{array}$ & 2 & 15 & 0 \\
\hline bone meal & $<1$ & 0 & 4 \\
\hline kelp & 0 & $15-30$ & 0 \\
\hline soft rock phosphate & 0 & 0 & 22 \\
\hline $\begin{array}{l}\text { potassium-magnesium } \\
\text { sulfate }\end{array}$ & & & 1 \\
\hline
\end{tabular}


The short-term availability of nutrients depends largely on the nature of the fertilizer material and how it was processed. Table 4 compares mineralization rates for various organic nitrogen sources at different temperatures. These fertilizers can be applied prior to planting or in one or more supplemental side-dressings.

Materials such as processed liquid fish, liquid soybean meal, or sodium nitrate may also be applied through drip irrigation systems. Some of these products contain small particles that are suspendable in water but not truly soluble; the water filtration necessary for microirrigation systems may remove these particles, lowering the nutrient content delivered to the crop. Dilute liquid "teas" from these materials are sometimes applied to the soil or sprayed directly on the plant in an effort to improve nutrient availability, but the value of these teas as a nutrient source has not been clearly established.

Certain by-products of the meat processing industry, such as blood and bone meals, have been restricted by some vegetable growers and shippers for market-related reasons. Mined Chilean nitrate (sodium nitrate), a source of nitrogen that is rapidly available to plants, was an important component of organic fertilizer programs in the past because of its relatively low cost, solubility, and ease of use. However, concerns that the mining and use of this product present environmental risks, as well as the widespread view within the organic movement that reliance on a soluble mineral nitrogen fertilizer is incompatible with organic principles, has limited its use in recent years. The NOP currently restricts the use of Chilean nitrate to no more than 20 percent of total nitrogen use and mandates that organic producers develop a plan to phase out Chilean nitrate use over time.

\section{Minor Element Sources}

Organic fertilizer sources commonly contain one or more minor elements. A number of liquid materials and teas are also available that provide one or more minor elements. Some of these materials may be used in irrigation systems or applied to foliage. Field trials evaluating the effectiveness of minor element foliar applications when soil nutrient levels are already adequate do not show a consistent pattern of crop response. The costs of these materials vary widely. Synthetic fertilizers may be permitted by a certifying agency in specific circumstances for correction of minor element deficiencies. Synthetic minor element fertilizers may contain hazardous materials used as fillers or other contaminants, and there is debate over the use of these materials, even in small amounts, in organic production systems.

\section{Special-purpose Fertilizers}

Specific approved nutrient sources of potassium, calcium, and magnesium may be useful to an organic grower when a deficiency or imbalance is indicated by a soil test. Materials such as gypsum, lime, and potassium-magnesium sulfate have been in use in agriculture for many years, and their value is thoroughly tested. These materials may be used to correct deficiencies or imbalances of potassium, calcium, or magnesium, or to raise soil pH. Gypsum is also used to improve water infiltration on soils with poor structure. Growers and researchers are still evaluating a number of other special-purpose fertilizers and growth enhancers. Materials derived from kelp and other processed seaweeds contain nutrients and often plant hormones and growth regulators. Some manufacturers claim that microbial soil stimulants enhance growth or reduce soil pests.

Table 4. Net nitrogen mineralization (as a percentage of initial organic nitrogen) from organic fertilizers, as influenced by temperature and length of incubation

\begin{tabular}{|c|c|c|c|c|c|}
\hline \multirow{2}{*}{ Product } & \multicolumn{2}{|c|}{ Temperature } & \multicolumn{3}{|c|}{ Net $\mathrm{N}$ mineralization during incubation $(\%)$} \\
\hline & ${ }^{o} \mathbf{F}$ & ${ }^{\circ} \mathrm{C}$ & 1 week & 4 weeks & 8 weeks \\
\hline \multirow{2}{*}{ pelleted poultry manure } & 59 & 15 & 4 & 16 & 21 \\
\hline & 77 & 25 & 10 & 23 & 36 \\
\hline \multirow{2}{*}{ sea bird guano } & 59 & 15 & 49 & 57 & 60 \\
\hline & 77 & 25 & 45 & 48 & 54 \\
\hline \multirow{2}{*}{ pelleted sea bird guano } & 59 & 15 & 42 & 61 & 64 \\
\hline & 77 & 25 & 46 & 60 & 67 \\
\hline \multirow{2}{*}{ fish powder } & 59 & 15 & 51 & 55 & 61 \\
\hline & 77 & 25 & 48 & 60 & 64 \\
\hline \multirow{2}{*}{ feather meal } & 59 & 15 & 42 & 56 & 59 \\
\hline & 77 & 25 & 50 & 64 & 63 \\
\hline \multirow{2}{*}{ blood meal } & 59 & 15 & 41 & 60 & 64 \\
\hline & 77 & 25 & 51 & 67 & 70 \\
\hline
\end{tabular}


Brix mixes, humates, foliar nutrient and sugar solutions, and other materials are applied to raise nutrient or sugar levels (Brix) in plant sap in an attempt to improve the plant's resistance to pests. There is scant scientific data supporting the efficacy or costeffectiveness of such products.

\section{CHARACTERISTICS OF ORGANIC FERTILIZERS}

Organic fertilizer materials share a number of characteristics that distinguish them from conventional fertilizers. The key features to consider in a fertility management program are bulk, nutrient availability, and uniformity.

\section{Bulk}

Many organic fertilizer materials (e.g., compost or other organic by-products) are generally less concentrated sources of nutrients than are conventional fertilizers. Application rates for these materials are commonly 5 to 10 tons per acre $(11.2-22.4$ $\mathrm{T} / \mathrm{ha}$ ), sometimes more. Growers need to consider how they will transport, store, and apply such large quantities of material. Larger storage facilities and special handling equipment may be necessary.

\section{Nutrient Availability}

Organic fertilizers often include both a relatively small proportion of readily available soluble nutrients and another nutrient fraction that is either unavailable to the plant or available only gradually over time. These materials as a group need to be applied earlier in anticipation of plant nutritional requirements, often 2 to 4 weeks before nutrients will be needed. The availability of nutrients depends on microbial activity: a lack of mixing with the soil or extremes of soil moisture or temperature will slow nutrient availability. The composition and particle size of the material can also be determining factors in the rate of microbial decomposition and nutrient availability. A more concentrated, finer-textured material generally decomposes and releases its nutrients more readily than does a coarser mixture.

\section{Uniformity}

Organic fertilizer materials can vary considerably with respect to particle size, moisture content, nutrient content, and nutrient distribution. Some of this inconsistency is inherent in the materials because of the nature of the production process and the fact that these are organic materials that continue to change during transport and storage. Growers should try to determine the composition of key fertilizer materials and keep records of their variations over time.
It may be worthwhile to send samples of composts and organic fertilizers to an independent laboratory for analysis.

The transitional period for new organic operations can be the most demanding in terms of soil fertility management. This is because the benefits of soil building and soil organic matter improvement have not yet been realized in a transitional field, but the grower is limited to only a few soluble fertilizer materials. Growers gain experience during the transitional period, and as the soil organic matter builds, its benefits are reflected in improved soil fertility. Approved materials lists have been developed by the NOP and include a broad range of materials to supplement crop nutritional needs. Materials from organic or natural sources may contain contaminants such as salts, heavy metals, and boron that may accumulate to toxic levels on a given field. Choose carefully from the materials available; know the source of the material and its composition.

\section{RESOURCES}

AgNIC (Agriculture Network Information Center) Web site, http://www.agnic.org.

Chaney, D. E., L. E. Drinkwater, and G. S. Pettygrove. 1993. Organic soil amendments and fertilizers. Oakland: University of California Division of Agriculture and Natural Resources Publication 21505.

Fundamentals of sustainable agriculture series. 1997-1999. ATTRA (National Sustainable Agriculture Information Service) Web site, http://www.attra.org/fundamental.html.

Hartz, T. K., J. P. Mitchell, and C. Giannini. 2000. Nitrogen and carbon mineralization dynamics of manures and composts. Hortscience 35(2):209-212.

Miller, P. R., W. L. Graves, and W. A. Williams. 1989. Cover crops for California agriculture. Oakland: University of California Division of Agriculture and Natural Resources Publication 21471.

NOP (USDA National Organic Program) Web site, http://www.ams.usda.gov/nop/indexIE.htm.

Organic production: Recent publications and current information sources. Alternative Farming Special Reference Brief SRB-01.

Parnes, R. 1990. Fertile soil: A grower's guide to organic and inorganic fertilizers. Davis, CA: Fertile Ground Books. 
Parnes, R. 1990. Fertile soil: A grower's guide to organic and inorganic fertilizers. Davis, CA: Fertile Ground Books.

Wyman, C., E. Chapman, and C. Sanders. 1990. Organic farming directory. Oakland: University of California Division of Agriculture and Natural Resources Publication 21479.

\section{OTHER PUBLICATIONS IN THIS SERIES}

Organic Certification, Farm Production Planning, and Marketing, UC ANR Publication 7247, 2006. ANR CS Web site, http://anrcatalog. ucdavis.edu/pdf/7247.pdf.
Soil Management and Soil Quality for Organic Crops, UC ANR Publication 7248, 2000. ANR CS Web site, http://anrcatalog.ucdavis. edu/pdf/7248.pdf.

Weed Management for Organic Crops, UC ANR Publication 7250, 2000. ANR CS Web site, http://anrcatalog.ucdavis.edu/pdf/7250.pdf.

Insect Pest Management for Organic Crops, UC ANR Publication 7251, 2000. ANR CS Web site, http://anrcatalog.ucdavis.edu/ pdf/7251.pdf.

Plant Disease Management for Organic Crops, UC ANR Publication 7252, 2000. ANR CS Web site, http://anrcatalog.ucdavis.edu/ pdf/7252.pdf.

To order or obtain printed ANR publications and other products, visit the ANR Communication Services online catalog at http://anrcatalog.ucdavis.edu. You can also place orders by mail, phone, or FAX, or request a printed catalog of our products from:

University of California

Agriculture and Natural Resources

Communication Services

6701 San Pablo Avenue, 2nd Floor

Oakland, California 94608-1239

Telephone: (800) 994-8849 or (510) 642-2431

FAX: (510) 643-5470

E-mail inquiries: danrcs@ucdavis.edu

An electronic version of this publication is available on the ANR Communication Services Web site at http://anrcatalog.ucdavis.edu.

Publication 7249

ISBN-13: 978-1-879906-96-9

ISBN-10: 1-879906-96-1

(C) 2000, 2006 by the Regents of the University of California, Division of Agriculture and Natural Resources. All rights reserved.

The University of California prohibits discrimination or harassment of any person on the basis of race, color, national origin, religion, sex, gender identity, pregnancy (including childbirth, and medical conditions related to pregnancy or childbirth), physical or mental disability, medical condition (cancer-related or genetic characteristics), ancestry, marital status, age, sexual orientation, citizenship, or status as a covered veteran (covered veterans are special disabled veterans, recently separated veterans, Vietnam era veterans, or any other veterans who served on active duty during a war or in a campaign or expedition for which a campaign badge has been authorized) in any of its programs or activities. University policy is intended to be consistent with the provisions of applicable State and Federal laws.

Inquiries regarding the University's nondiscrimination policies may be directed to the Affirmative Action/Staff Personnel Services Director, University of California, Agriculture and Natural Resources, 1111 Franklin St., 6th Floor, Oakland, CA 94607-5201 (510) 987-0096. For a free catalog of other publications, call (800) 994-8849. For help downloading this publication, call (530) 297-4445.

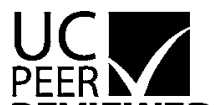

REVIEWED

This publication has been anonymously peer reviewed for technical accuracy by University of California scientists and other qualified professionals. This review process was managed by the ANR Associate Editor for Vegetable Crops.

rev-4/07-SB/RW revised April, 2007 